\title{
Congenital lactase deficiency
}

INSERM

\section{Source}

INSERM. (1999). Orphanet: an online rare disease and orphan drug data base. Congenital lactase deficiency. ORPHA:53690

Congenital lactase deficiency is a rare severe gastrointestinal disorder in newborns primarily reported in Finland and characterized clinically by watery diarrhea on feeding with breast-milk or lactose-containing formula. 